\title{
Simple Acrylic Color Technique for the Preparation of Wet Specimen in Anatomy Museum
}

\author{
*Sunil Shrestha ${ }^{1}$, Prabhakar Yadav ${ }^{2}$, Samyog Mahat $^{3}$, Shamsher Shrestha ${ }^{4}$ \\ ${ }^{1}$ Postgraduate Student, ${ }^{2}$ Associate professor, ${ }^{3}$ Senior resident, ${ }^{4}$ Additional professor, Department \\ of Human Anatomy; B.P. Koirala Institute of Health Science (BPKIHS), Dharan, Nepal
}

\section{Corresponding Author:}

Sunil Shrestha, Email: sunilmanshrestha@gmail.com

\begin{abstract}
Introduction: The subject anatomy is an essential subject in medical college for students and museum with attractive, an innovative colored specimen with well-labeled specimen aids a pivotal role in the teaching and learning process. Once the specimen has been selected for coloring, undergoes fixation, acrylic paint coloring, plastic bottle mounting and proper labeling for better visualization of the structure.

Method: We have utilized a simple acrylic color method for painting the gross specimen available for the teaching and learning process from well-embalmed cadavers. The materials required are acrylic color paint, brush, clear nail polish, glycerin, clear plastic bottle, $10 \%$ formaldehyde and can be performed at room temperature.

Result: The acrylic coloring technique of wet specimen makes specimen attractive which is costeffective, non-toxic, creates great interest and aids long term memory to the student.

Conclusion: The acrylic painted wet gross specimen with clear plastic bottle mounting remains stable in $10 \%$ formalin without color fading and makes students a better understanding of the subject.

Keywords: Color specimen, Anatomy museum preparation, Acrylic painting, Plastic mounting
\end{abstract}

\begin{tabular}{|c|c|c|}
\hline \multicolumn{2}{|c|}{ Access this article Online } & Articlelnfo. \\
\hline \multirow[t]{7}{*}{ Quick Response Code } & Website: & Howtocitethisarticle in Vancouver Style? \\
\hline & www.jkahs.org.np & \multirow{2}{*}{$\begin{array}{l}\text { Shrestha S, Mahat S, Yadav P, Shrestha S, Amgain } \\
\text { K. Simple Acrylic Color Technique for the } \\
\text { Preparation of the Wet Specimen in the Anatomy } \\
\text { Museum. Karnali Academy of Health Sciences } \\
\text { 2020;3(1): }\end{array}$} \\
\hline & \multirow{5}{*}{$\begin{array}{l}\text { DOI: } \\
\text { https://doi.org/10.3126/jkahs.v3i1. } \\
27732 \\
\text { The DOI will be functional after } \\
\text { the issue is fully published online } \\
\text { as well as in printed version }\end{array}$} & \\
\hline & & Received:6 Dec. 2019 \\
\hline & & Accepted:14 Feb. 2020 \\
\hline & & Published Online:15 Feb. 2020 \\
\hline & & Conflict of Interest: None, Source of Support: None \\
\hline
\end{tabular}




\section{INTRODUCTION:}

A museum is an institute that "displays a collection of the scientific or artistic artifact with significance to a specific group of visitors". The concept of anatomy museum plays a dominant role which was conceived by Edinburg surgeons during 1700-1763 AD. In 1868, the anatomy museum evolves significantly due to the discovery of formalin. ${ }^{1}$ Anatomy is an integral part of medical science which is the study of the human body, organs, soft parts, hard parts, and structures are presented via the museum. ${ }^{2}$ In the 19th century, the subject comes in limelight as a prerequisite for the medical profession and soon become the very essential curriculum for medical education programs with the norm "No dissection, no knowledge". Soon embalming preservation technique was developed and the structure was preserved with various possible variations and placed in the museum. ${ }^{3}$ The effectiveness of the anatomy museum is based on viewing the three-dimensional structure of the object is better remembered than written or verbal description and attractive, innovative with a well-labeled colored specimen in the museum plays an important role in educating a student that provides indepth knowledge of gross structure. ${ }^{4}$ To make the specimen attractive the most commonly used color is acrylic paint which is flexible, non-toxic, versatile and further enamel is added which forms glossy, opaque finish and provides attractive, excellent coverage and color retention. ${ }^{3}$ The colored specimen with proper labeling is utmost important that support teaching and learning gross anatomy and makes specimen more attractive and adds aesthetic value.

\section{MATERIALS \& METHODS:}

The wet specimen selected for the coloring technique were obtained from the well arterial embalmed cadavers of department of human anatomy, B.P. Koirala Institute of Health Sciences, Dharan, Nepal and ethically approved specimenfor research, teaching and learning process. The arterial embalming was performed to the cadaversusing formalin base conservative preservation technique and cadavers were dissected meticulously for teaching learning and organs were preserved further in formalin for museum. The materials used for coloring the wet specimen were commercially available Acrylic paints as shown in figure 1, transparent nail polish, turpentine oil and painting brush of different size.

The five steps to prepare the wet colored specimen as follows

1. The dissected organs obtained from arterial embalmed cadaver was used as wet specimen which was first identified for the coloring and allowed for drying properly for 2 to 3 days, and further allowed to dry for additional days if not dried properly at room temperature.

2. After drying, on glass plate acrylic paint color were chosen and those structures which dry first such as vessels and nerve were painted first with specific color as mentioned in an atlas and later other structure were painted accordingly and turpentine oil is used for clearing the brush.

3. The specimen was allowed to dry for 5-6 hours and another coat of same paint was added to it simultaneously and check for missing area of paint thoroughly, now coat with transparent nail polish paints.

4. Now, the specimen was further allowed to dry completely for 1 to 2 days.

5. At last, the color codes can be done for labelling and specimens were kept in the glass jar with a $10 \%$ formalin solution supported with glass rod or clear plastic water bottle ${ }^{2}$ as shown in figure 3 and 4 or wood with nails 2 as shown in figure 6. Finally, jar is 
covered with lid and sealed with cello tape or wax.

\section{RESULT:}

The creation of extraordinary museum specimen is only possible after proper planning of color and proper mounting for the presentation of the specimen without damaging. The five-step technique that we have used for coloring the various structure of abdominal and thorax region specimen were painted with anatomically correct color as mentioned in atlas and specimen were preserved in $10 \%$ formalin which was mounted with clear plastic bottles as shown in figure 3 and 4. No leakage, mixing of color was observed for six months with acrylic paint coated with clear nail polish to small structure and impression, since the materials used were nontoxic, commercially easily available in the stationary shop, and easy to handle. The coloring technique of wet specimen makes better understanding of the gross features and adding clear nail polish brings glistening effect to specimen and relations of the structure can be studied.

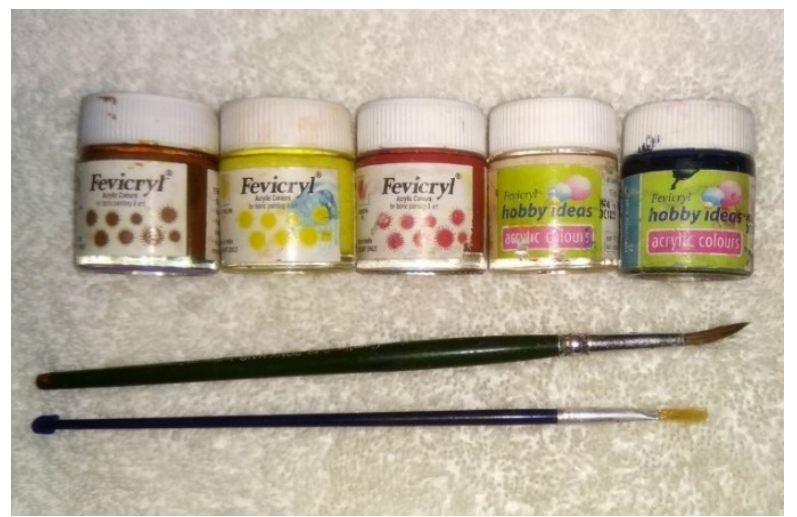

Figure 1: Figure showing acrylic paints with brushes

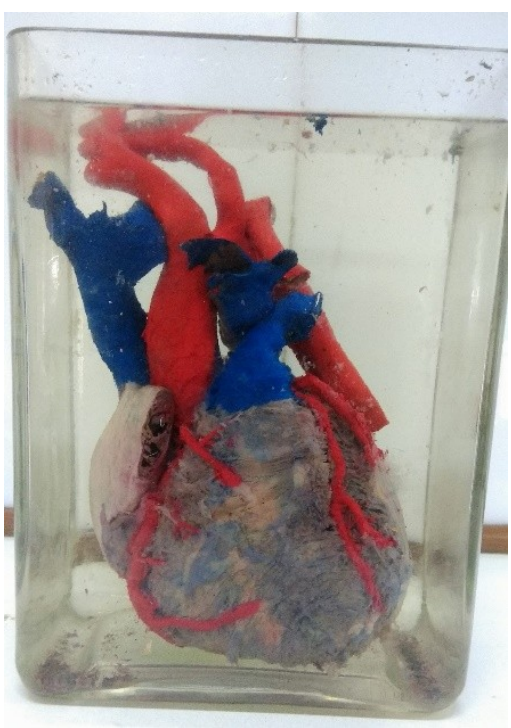

Figure 2: Figure showing gross specimen of heart with its arteries and vein

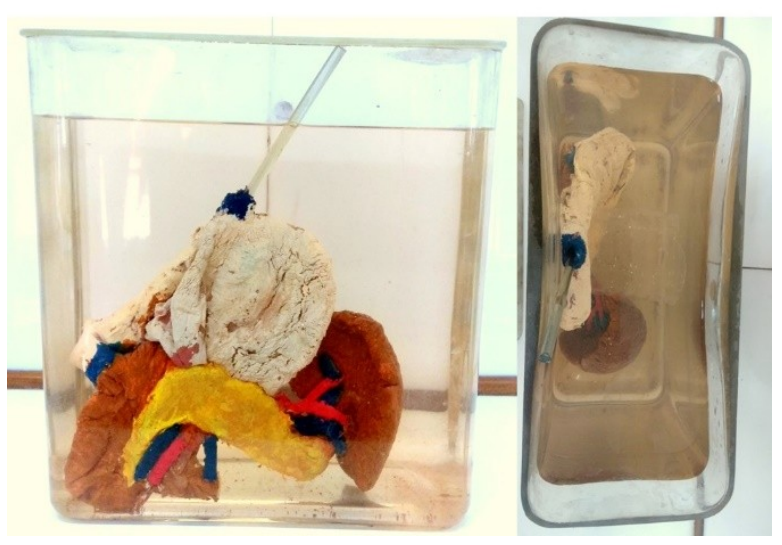

Figure 3: Figure showing relation of stomach, duodenum, pancreas $\&$ spleen and its mounting technique with plastic bottle 


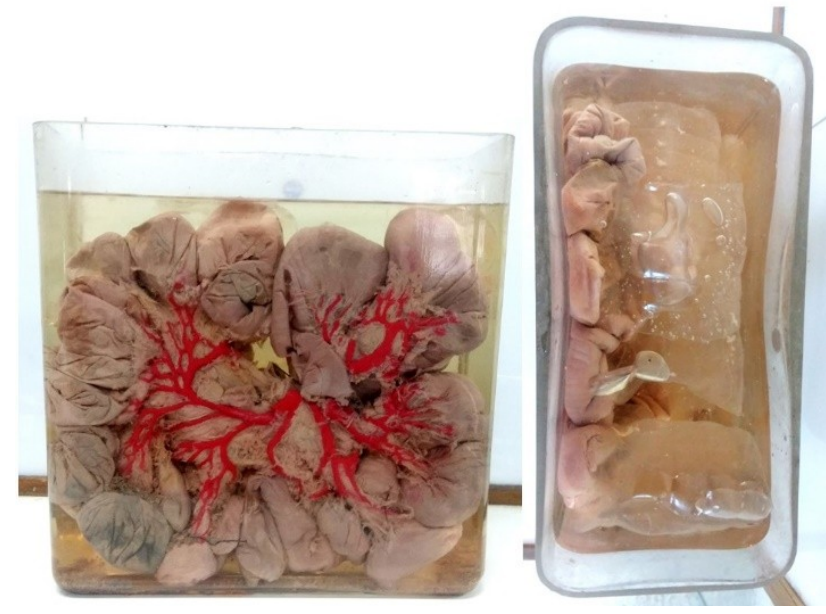

Figure 4: figure showing jejunal\&ileal branch of mesenteric arteries with its mounting technique with plastic bottle

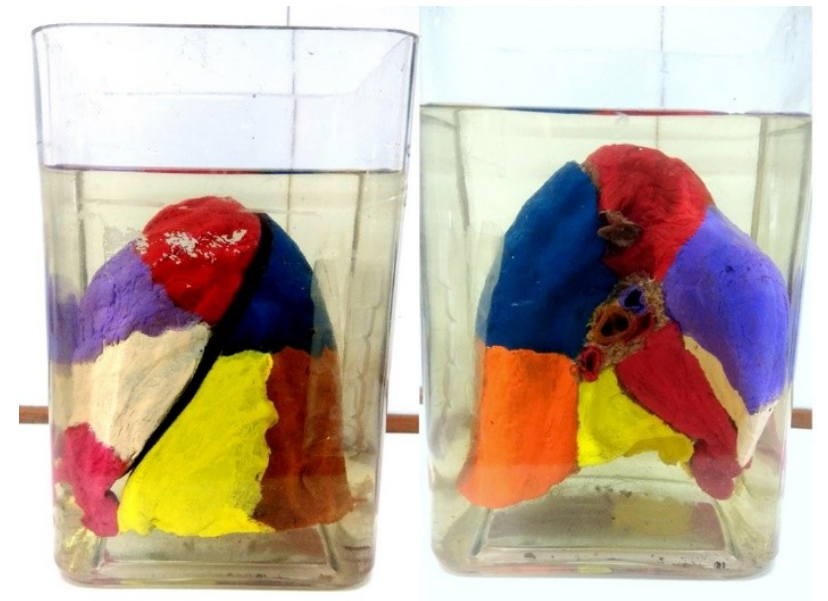

Figure 5: Figure showing Bronchopulmonary segment of left lungs

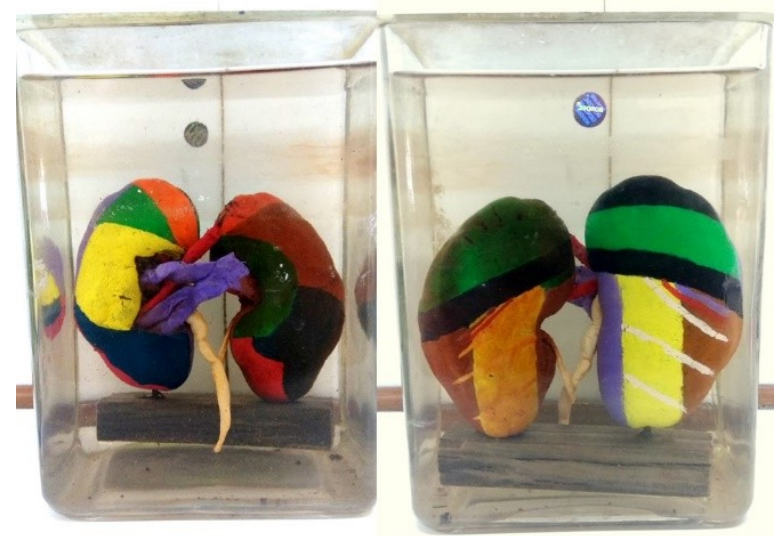

Figure 6: Figure showing anterior and posterior relation of right \& left kidney and mounted with nail inserted in wood

\section{DISCUSSION}

The color specimen used in the teaching anatomy attenuates high value for the student in medical school and coloring also createsinterest of student towards anatomy and adds long term memory. Many researchers have used different techniques and different material colors such as albuminous paint, lacquer, silicone, calmin oil paint and acrylic paint from time to time. The use of acrylic paint with transparent nail polish can dry out very quickly and easily available in the market and also supported by Kaur $\mathrm{N}$ et al who explained that acrylic paint can produce film of great clarity and use of transparent nail polish which contains nitrocellulose resin, adhesive polymers, solvents, and coloring agent is cost-effective, non-toxic and prevents running of color in the mounting fluid. 3,4

The proper drying of the wet specimen should be done before coloring the specimen and that structure which dry first should be colored first was also supported by Jain $\mathrm{L} \mathrm{K}$ et $\mathrm{al}^{5}$ and Prabhu L V et $\mathrm{al}^{4}$. The use of clear nail polish directly over specimen doesn't allows the observable fading of acrylic color because it increases the binding capacity and prevents color peeling in formalin which was also supported by Kaur N et al and Prabhu et al. ${ }^{3,4}$ The mounting is also important for the preservation of the specimen, the technique used in this was mentioned by Jain $\mathrm{L} \mathrm{K}$ et al, who explained that colored specimen placed in glass or jar filled with $10 \%$ formaldehyde solution can be easily supported by transparent plastic bottle without use of needle and thread. He focused that the use of plastic bottles not only supports the specimen but it enhances the looks without damaging it. $^{2}$ Kaur $\mathrm{N}$ et al also enhances the use of adding glycerin with $10 \%$ formaldehyde which acts as the clearing agent and can improve the optical properties with fine structural details. $^{3}$ 
The colored specimen with proper labeling adds aesthetic value that supports teaching and learning anatomy and makes specimen attractive was supported by Garsa V et al who researched over the teaching anatomy with atlas and colored specimen over student and concluded that incorporation of color in dissected prosection makes understanding the subject bit easy. ${ }^{6}$ The study was also supported by the Mogali SK et al who studied over the medical student about the educational value of multicolored threedimensional models for anatomical education and reported that 3D models are less realistic compared to plastinated model but an excellent adjunct to wet cadaveric or plastinated prosection. ${ }^{7}$ but Suganthy $\mathrm{J}$ et al claimed that colored plastination add value to teaching tool using costly list of reagent but acrylic paint can lead to patchy coloring and lose their educational value. ${ }^{8}$ Therefore, Mcmenamin PG et al concluded that Production of anatomical teaching resources using three-dimensional printing technology is necessary though $3 \mathrm{D}$ model are less realistic because accessing human cadaver is concerned with health safety consideration for student and may have hazardous effect due to exposure with formalin and it may be the alternative approach for anatomical specimen reproduction. ${ }^{9}$ Tan $\mathrm{L}$ et al also supports the Mcmenamin et al and explained that virtual interaction mode can mimic actual anatomical specimen observation and dissection which can provide realistic and reusable teaching resource and improve the quality of anatomy teaching. ${ }^{10}$ Therefore, Acrylic color technique at room temperature for wet specimen allows the specimen to be stored in formalin without color fading and well-labeled specimen aids memory makes specimen attractive with distinguishing anatomical structure and creates interest of student towards gross anatomy with better understanding relation of different structure .

\section{CONCLUSION}

The acrylic colored anatomically painted specimen with clear plastic bottle mounting technique remained stable in $10 \%$ formalin solution which brings life to specimen and makes specimen attractive. Therefore, long term preservation of colored specimen in anatomy museum is ensured indeed.

\section{ACKNOWLEDGEMENTS}

We would like to thank Prof. Dr Chandra BhushanJha, HOD, Department of Human anatomy, BPKIHS and to all who donated their body for the education and research purpose.

\section{REFERENCES:}

1. Kamath VG, Avadhani R. Archives of anatomy from the $17^{\text {th }}$ to $21^{\text {st }}$ century. Arch Med Heal Sci. 2016;4(1):135-43. $\underline{\text { Google Scholar }}|\underline{\text { CrossRef }}| \underline{\text { Full Text }}$

2. Jain LK, Babel H, Vijay N. New technique to mount specimen in the formalin filled jar for anatomy museum with almost invisible support. Int J Cur Res Rev. 2013;05(12):45-50. Google Scholar | Full Text

3. Kaur N, Agarwal RK, Khajuria S, Harsh, Saini H. Technique for Preserving Colored Wet Specimen in Anatomy Museum. Int J Anat Res. 2017;5(2.2):3824-8. CrossRef $\underline{\text { Full Text }}$

4. Prabhu L V, Pai MM, Premchandran D, Murlimanju B V, Vadgaonkar R. A novel meethod for coloring and labelling specimens in the anatomy museum. Int $\mathbf{J}$ Anat Res. 2015;3(2):1165-7. $\underline{\text { Google Scholar }}|\underline{\text { CrossRef }}| \underline{\text { Full Text }}$

5. Jain L kumar, Babel H. Method of colouring wet specimen in anatomy. Int $\mathbf{J}$ Cur Res Rev. 2014;6(22):20-3. Google Scholar | Full Text 
6. Garsa V, Narayan RK, Gahlawat N, Gupta S. Teaching anatomy with atlas \&coloured specimen. Int Journal Appl Res.

2017;3(4):518-20.

$\underline{\text { Full Text }}$

7. Mogali SR, Yeong WY, Kuan H, Tan J, Jit G, Tan S, et al. Evaluation by Medical Students of the Educational Value of Multi-Material and Multi-Colored ThreeDimensional Printed Models of the Upper Limb for Anatomical Education. AnatSci Educ. 2017;11(1):54-64. $\underline{\text { Google Scholar }}|\underline{\text { CrossRef }}| \underline{\text { Full Text }}$

8. Shanthi P, Francis DV, Suganthy J. Colourplastination - A valuable tool for medical education. J AnatSoc India. 2015;64(2):152-4.

$\underline{\text { Google Scholar }}|\underline{\text { CrossRef }}| \underline{\text { Full Text }}$

9. Mcmenamin PG, Quayle MR, Mchenry CR, Adams JW. The Production of Anatomical Teaching Resources Using Three-Dimensional (3D ) Printing Technology. AnatSci Educ. 2014;7(6):47986.

$\underline{\text { Google Scholar }}|\underline{\text { CrossRef }}| \underline{\text { Full Text }}$

10. Zhang X, Yang J, Chen N, Zhang S, Xu Y, Tan L. Modeling and simulation of an anatomy teaching system. Vis ComputInd Biomed. 2019;2(1):1-8.

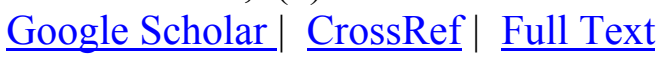

